Cult Med Psychiatry. 2015 June ; 39(2): 299-321. doi:10.1007/s11013-015-9443-x.

\title{
Making Meaningful Worlds: Role-playing Subcultures and the Autism Spectrum
}

\author{
Elizabeth Fein, Ph.D. \\ Assistant Professor, Department of Psychology, Duquesne University
}

\author{
Keywords \\ autism; asperger's syndrome; LARP; neurodiversity
}

\section{Introduction}

This paper examines the affinity between forms of neurological variation often diagnosed as autism spectrum disorder and a set of cultural practices, narratives, and relationships coalesced around the playing of live-action roleplaying games (LARP's). Situated at the points of intersection between cognition and cultural materials, this ethnography examines the ways that neurocognitive specificities create and shape cultural spaces; such spaces in turn serve as potentially transformative resources for participants who are struggling with difficulties in living.

While also informed by longer-term follow-up, this paper draws primarily on two months of ethnographic fieldwork at a summer camp for youth on the autism spectrum in a small town on the East Coast of the United States, at the beginning of my two-year ethnographic study of autism spectrum conditions ${ }^{\mathrm{i}}$ in that region. The camp was created by the Journeyfolk $\mathrm{k}^{\mathrm{ii}}$, a group of youth dedicated to the art of live-action roleplaying games. These games combine elements of collaborative story-telling, improvisational theater, and table-top roleplaying games such as Dungeons and Dragons. Participants create and enact stories of epic battles and quests, playing characters who might be heroes or rogues or a little bit of both, as they seek to slay enemies, solve puzzles, and achieve both group and individual objectives. The camp I studied was inspired by an observation, by the founder of the Journeyfolk, that youth on the autism spectrum were intuitively drawn to these games, and seemed to thrive within them.

Why were these games so effective for engaging youth on the autism spectrum in complex and difficult social tasks? Why were these youth so enthusiastic about them? Based on my observations of the camp, my interviews with campers and staff, and my understanding of autistic cognition and phenomenology (drawn also from cognitive science and autistic autobiography), I argue that the camp engaged participants by being congruent with their

i I use the phrase "autism spectrum conditions" (rather than "autism spectrum disorders") in recognition of the fact that the condition I am describing contains elements of both ability and disability, vulnerability and strength, order and disorder.

ii The names and identifying details of all programs and participants have been changed in order to protect their privacy and confidentiality. 
needs on three levels: in the structure of its practices, the narratives that comprised its mythology, and the nature of its community. The structured social practices of roleplaying, from the character design sheets to the genre-specific formality of interactions, constituted a sociocultural ecology affordances of which provided the support and organization participants needed for successful social coordination. The central narratives of the game, which tended to focus on conflicted internal forces of darkness and light, provided a shared mythology within which the emotional and behavioral turbulence characteristic of autism spectrum conditions was re-interpreted as a source of power and strength, motivating acceptance rather than exclusion. The community of the camp, and the community center with which the camp was associated, provided a space where characteristics associated with autism were shared and valued, even among those counselors who were not themselves diagnosed with autism spectrum conditions. Autism spectrum conditions thus became common ground for a sense of belonging, rather than a source of estrangement and isolation. Attractive and congenial to campers for all of these reasons, this clustering of particular practices, narratives, and interpersonal ethos was reinforced and reinvented through their creative engagement.

The camp thus serves as an example of what (Obeyesekere, 1990) calls "the work of culture," defined as "the process whereby symbolic forms existing on the cultural level get created and recreated through the minds of people" (xix). Here, I am also following Chapin's (2008) call to "extend Obeyesekere's conception of 'the work of culture' beyond the domain of meaning and symbol to include roles for embodied practice and interpersonal relationships." As Obeyesekere notes in Medusa's Hair, individuals work through their internal conflicts through the use of public symbols, and such symbols "would cease to exist (except in texts and nonliving icons) if individuals did not create [them] each time on the anvil of their personal anguish" (33). In their lively animation of these structured practices, narratives, and relational networks, the campers have given these existing forms a new manifestation.

This paper thus seeks to explore not only the ways in which subcultural communities shape the meanings of neurodiversity, but also the way that neurodiversity shapes culture.

Patterned neurocognitive variations, including but not limited to those seen in clinical conditions such as autism, help to organize practices and social orientations into familiar sets. Some of these will become deeply meaningful to participants, providing opportunities for healing and social integration. Autism spectrum conditions, which are often thought to preclude sociocultural participation, can thus serve as a force for the organization of culture.

\section{Transformative Stories: The Legend of Aedril}

Many years ago, the townsfolk of Rentin were attacked by an army of orcs, led by the Orc King. Fortunately, a great hero, named Aedril, defeated and imprisoned the Orc King. But this year, we have accidentally set the Orc King free. He has raised up a terrifying creature-a Golem—and is menacing the town. A team of adventurers-Aura Dragonsblood, Feriek Ravensclaw, Murdoch the Muscle Man, and Ray - have assembled to fight the Orc Armies and the Golem. It turns out, however, that the Golem is the dark side of Aedril: his violence, his rage. $\mathrm{He}$ 
separated these things from himself and cast them away, believing that this was what he must do to become a great hero. Now the adventurers—guided by a wise witch, and accompanied by the King and Queen of Rentin-must conduct a magic ritual that re-unites the Golem with the ghost of Aedril. Only by integrating both sides of their hero can the people of the village be at peace.

Each week, we participants at the camp created and enacted a different story; "The Legend of Aedril" was the story we played during the last week of camp. Like most of the stories we played, "The Legend of Aedril" was a quest narrative organized around a psychological theme: the difficulty, and great importance, of accepting an integrated self that contains both aggression and wisdom, both impulse and reason, both chaos and control. In each of these stories, the basic premise was drawn from a trove of narrative frameworks curated by the Journeyfolk. The players, however, added their own elements to the story, and the twists and turns of the plot hinged on the decisions of the adventurers, guided by the creatures they encountered along the way.

\section{The Cast of Characters: Who's Who, Under What Circumstances}

The adventurers were played by the campers-an eclectic and somewhat unpredictable group. Some were tall and gangly, others tiny and round; some were socially withdrawn while others were anxious to share their every thought and feeling with the world. Some came from affluent families; others could not have attended if the small camp fee had not been waived for them. All of them were between the ages of eleven and eighteen, and all had been diagnosed with an autism spectrum condition. Most commonly, that diagnosis was Asperger's Syndrome, a condition characterized by impairments in social relatedness and restricted, repetitive behaviors, without significant language impairment or intellectual disability, which is often associated with intense interests and a dramatically uneven profile of cognitive weaknesses and strengths ${ }^{\text {iii }}$. However, how this condition manifested was very different for each. Andrew was bouncing-off-the-walls hyper, constantly asking questions but never seeming to listen to the answers. Cody almost never spoke; all of his words went into the novel he was writing, eighty pages long and growing. Christy was painstakingly polite, cautiously considering the ramifications of her every move. Gunnar ran out of the room howling if anyone touched him when he was not expecting it; he also liked to jump on people unexpectedly, to see what they would do. What they all had in common, though, was that they were all working very, very hard to do things that others might take for granted: to keep their sensory perceptions integrated into coherence, to organize their thoughts into patterns that made sense to them and to others, and to keep from being overwhelmed by rage, fear, and sadness.

The fairies, trolls, and other creatures that they interacted with along the way were "nonplayer characters," or NPC's, played by staff. Their goal was not to win the game, but instead to manage the story and keep it moving forward. The army of orcs that the campers battled, for example, were played by the Counselors in Training. Older teens, also diagnosed

\footnotetext{
iii The most recent revision of the Diagnostic and Statistical Manual of Mental Disorders (American Psychiatric Association, 2013) combines several previously separate subtypes of autism, including what was previously called Asperger's Disorder, into a single category of Autism Spectrum Disorder. At the time of this research, Asperger's Syndrome was still a separate category in active use.
} 
with Asperger's, they had spent the beginning of the summer as campers going on adventures. Now, in the second half of the summer, we challenged them to put aside their own desire to play the hero, and take on the task of making sure the new, younger campers had a great time defeating monsters that were ferocious, but eventually defeasible.

Other characters - the witch, the King, the magical creatures from whom the adventurers had to obtain magical objects-were played by the camp counselors, drawn from the Journeyfolk. Several years earlier, the founder of the Journeyfolk, a teacher I call Mark, had started to notice that kids and teenagers with Asperger's Syndrome responded particularly well to the kind of activities offered at the Journeyfolk summer camps. They seemed to get really "into character," he told me, playing their roles with an enthusiasm and depth of commitment usually only seen in more experienced players. And they loved the games. But they could not always handle the overwhelming, immersive social life of the sleepaway camps. So Mark started working with the Unity Center, a community center dedicated to cultivating pride and self-advocacy among youth and adults on the autism spectrum, to design Asperger-specific programming. A core group of staffers were selected from among the most seasoned of the Journeyfolk counselors to run what came to be called "the Aspie camp" iv; other counselors from the main camp occasionally showed up to help us out.

\section{Brunhilde, Valkyrie Queen of the Ethnographers: Roleplay in Fieldwork}

They also had an ethnographer. At the camp, I played a number of roles: anthropologist, counselor, winged fairy guardian of traveling adventurers. By day, I fought sword duels and faced down troll armies. I helped the campers develop their characters and manage their conflicts, and tried to keep them focused on workshops that taught them the fundamentals of improvisational roleplay, character development and spellcasting. Since I am also trained as a clinical psychologist, I provided clinical backup and consultation to the staff. By night, I wrote up fieldnotes and conducted interviews with the staff and campers. I slept at the main Journeyfolk campground, in the building where the costumes were sewed and sets built, and on weekends, I played in the games at the larger Journeyfolk camp. These were massive production numbers with upward of 50 players, elaborate costumes and scenery, and way more sex, violence, and tragedy than we could get away with at the "Aspie camp."

Balancing these roles was a messy, often anxiety-provoking situation. On the one hand, I strove to follow a sort of anthropological Prime Directive ${ }^{v}$, observing how the culture of the camp operated without introducing my own preoccupations and practices. On the other hand, as counselor and clinician, I often felt compelled to question, and sometimes intervene upon, the sort of practical matters that instantiate deeper ideologies about structure and safety. I fretted, in our staff meetings, about closure and containment: making sure the camp day started and ended on time, making sure that we had enough time in our "closing circle"

\footnotetext{
iv“"Aspie" is an affectionate shorthand for "person with Asperger's Syndrome"; unlike such "person-first language"; however, the term does not imply separation between the condition and the person. It is thus popular among members of the autistic self-advocacy movement who champion such "identity-first" language for autism spectrum conditions, because they consider these conditions to be intrinsic and often valued elements of their identity. When I use adjectives like "autistic" rather than "with autism" in this paper, I am doing so in the same spirit.

${ }^{V_{T}}$ This term refers to a mandate followed by the protagonists in Star Trek. It dictates that Federation members will not interfere with the social development of the societies they encounter.
} 
to process the day's events with campers, making sure that all the torches by the lake had been put out. I took a lot of notes about these conflicts, and they helped me understand some of what makes the Journeyfolk so different, in their wild creative energies, from the more sterile and standardized care environments within which I had trained. As I changed the camp, the camp also changed me. In one game, I played the role of Brunhilde, Queen of the Valkyries; the next week, in a conflict with another counselor, I felt myself calling up her imperious voice and stance to lend force to my own. I learned, over time, to be a more flexible and gracious collaborator and storyteller, and the Journeyfolk gradually entrusted me with more responsibility for the critical task of managing the flow of the story in our games.

\section{Your Princess Is In Another Castle: The Broader Ethnographic Study}

When I planned my dissertation research, I had not envisioned myself running through starlit fields carrying a giant staff and riding an imaginary dragon. My project aimed to examine how individuals affected by Asperger's Syndrome and related autism spectrum conditions-people diagnosed with these conditions, their families, and the professionals who worked with them-negotiated the contested meanings of this new diagnostic category. In particular, I was interested in how they reconciled tensions between two widely prevalent ways of understanding autism: as a disease to be cured or prevented, entirely negative and separable from the affected person, or as a constitutive aspect of the affected person's identity, to be protected and perhaps even valued. The Unity Center took the latter stance, encouraging the youth it served to take pride in an autistic identity and build on the strengths that came with their condition while also managing its challenges. So I had come there to conduct the first six months of a multisited, comparative ethnography that wound up also including a psychiatric clinic in a major medical center, four junior high and high school classrooms, and several support groups, all working with people diagnosed with autism spectrum conditions of the Asperger-like sort. Just prior to my arrival, the Director invited me to help out with the camp and I agreed, thinking it would be a good opportunity to immerse myself in life at the Unity Center.

Roleplaying games had thus not been a focus of my research project. But I soon started to observe intriguing thematic overlaps between the issues that emerged in game and the questions I came to the Unity Center to study. Again and again, I saw the Aspie campers create characters who wrestled with alien forces within: demon possession, monstrous ancestry, human-inhuman hybridity. These forces brought great powers and exacted great cost. They were both a pervasive and constitutive part of the affected person's identity, and deeply disruptive of it. These stories sounded a lot like what these youth were also telling me, in our interviews and in casual conversation, about what it was like to be on the autism spectrum.

Once the summer ended, I continued my study of how people affected by autism spectrum conditions define those conditions, to themselves and to others. I remained in the region for the next eight months, during which time I stayed in contact with many of the campers and the staff and had the chance to get to know them (and sometimes interview them again) in the context of their daily lives. Data collection and analysis was an iterative process; I 
returned to the area a year later, following a dedicated period of data analysis and clarification of themes, for followup.

Over the course of those two years, I had many opportunities to speak with the youth I'd gotten to know at the camp about their autism spectrum diagnosis, and their thoughts, feelings, and opinions around it. They politely put up with my questions, and did their best to give me good answers to my interview questions. But for the most part, what they really wanted to talk to me about was the camp. When was the camp going to start again? Could they show me their sketches for the sword they wanted to make? Could we go fight a sword duel in the backyard? Could they tell me about this great story idea they had? OK, could they tell me about it again? "I truly think it is the best kind of entertainment there is" Leo, one of the CIT's told me. The immense importance that the camp took on in the lives of campers left me with questions about the nature of its power, which I have taken the opportunity to explore here.

\section{The Alluring Therapeutics of Role-Play}

What is it about the collaborative, sword-wielding storytelling of the Journeyfolk that inspired such intense enthusiasm and loyalty among a group of teenagers (mostly boys) with Asperger's Syndrome? This is a population not usually thought of as joiners, known for their trepidation around group activities and physical play (Atwood, 2007; Safran, 2002).

Furthermore, live-action roleplaying pulls on the very abilities thought to be most impaired in people on the autism spectrum: perspective-taking, non-verbal communication, and above all, the discursive establishment, coordination and maintenance of shared mental abstractions (see Frith, 2012 for a review). Roleplay requires participants to step into someone else's shoes (figuratively and sometimes literally) — to walk and talk as the character would, to bracket one's own reactions and make decisions as the character would. It requires collaborating with others to create a shared imaginary world, held together by coordinated social interactions. What is it that made the Aspie campers so enthusiastically join in an activity that posed them such a tremendous set of challenges?

I argue here that the Aspie camp constituted an assemblage of cultural resourcesstructures, stories, relational commitments-through which the challenges associated with autism spectrum conditions became less impairing, and in many cases, became opportunities for mutual recognition rather than rejection. The basic structure of roleplaying games were congruent with what participants needed from their cultural ecology in order to organize themselves and their interactions. The narratives invoked at the camp provided a framework of meaning within which a chaotic, wild, mixed-up way of being could be accepted and welcomed. The turbulent internal experience of the campers, often a source of isolation and social estrangement in their daily lives, was reformulated as shared, potentially generative, and a little bit romantic. The relationships between participants (both campers and counselors) supported emotional risk-taking and modeled a continuum of successful development along which campers could progress. In what follows, I will describe these condition-culture affinities in more detail, drawing on experimental and ethnographic research on autism and cognition. 


\section{The Need for External Structure in Autism Spectrum Conditions}

A significant body of research has attempted to sort out the kinds of cognitive differences that might underlie autism spectrum conditions. No single account has been able to explain the wide variety of differences that tend to co-exist in autism spectrum conditions; however, several theories have received significant empirical support. Most prominent have been those related to limitations in theory of mind (the ability to conceptualize and reason about other people's internal states, i.e., Baron-Cohen, 1995, Kana et al., 2015), weak executive function (the ability to organize and manage one's cognitive processes in a flexible way, i.e., Ozonoff et al. 1991; Pennington and Ozonoff 1996; Granader et al. 2014), and bias toward local over global coherence (the tendency to focus on details, and calculate precise relationships between those details, rather than synthesizing them intuitively into a bigpicture gestalt, i.e., Happé and Frith, 2006). Baron-Cohen et al. (2003) have suggested that a preference for systematizing (analyzing variables in a system to discern their underlying rules) over empathizing (intuitively inferring the internal states of others) may be fundamental to the autistic cognitive style, arguing that some of the social struggles experienced by people on the autism spectrum result from a fruitless search to find the systems that reliably predict human behavior. Similarly, in a series of tests of social cognition, Baez et al (2012) found that adults with Asperger's Syndrome showed reduced ability to use implicit contextual cues to access social meaning; their performance was normal, however, when given explicit social information, or when the situation could be navigated using abstract rules.

It is increasingly clear that no one theory will explain all aspects of autism, and that not all people with an autism spectrum diagnosis fit all of these descriptions (Brunsdon and Happé, 2014; Vanegas and Davidson, 2015). Taken together, however, these theories suggest something about the relationship between the lived experience of autism and culture, as Geertz (1973) describes it: as the "extragenetic, outside-the-skin control mechanisms... plans, recipies, rules, instructions (what computer engineers call 'programs') for the governing of behavior" (44) without which human behavior becomes incoherent. What all of these neurocognitive characteristics have in common is that they produce an unpredictable and inconstant experiential world, and subsequently, increase the need for external systems to organize and structure complex experience. People with a locally coherent processing style have trouble making integrated wholes out of the sum of parts and coherent stories out of disconnected strings of events; they have difficulty seeing the forest for the trees.

Researcher Uta Frith has memorably described the consequences of local coherence as "an incoherent world of fragmented experience" (1989, see also Olu-Lafe et al, 2014). Problems inferring the motivations of other people can make human behavior seem capricious, incomprehensible, and utterly unpredictable. Limitations in executive function disrupt the continuity of time, attention, and intent, making it difficult to self-regulate and plan. Compounding these problems with organization, people on the spectrum often have difficulty processing incoming sensory input: sounds, smells, tastes, the brightness of light and the babble of voices in a crowd (Dunn, et al., 2002; Baranek 2002). In autobiographical writing (i.e., Prince-Hughes ed., 2002), people on the spectrum often report that it is exhausting to try to integrate all the information and sensation coming at them at any given 
moment, and that they often become "overwhelmed" in a chaotic and disorganized rush of reactions, impressions and emotions. This overwhelmed state can lead to "meltdowns": profound alterations of consciousness associated with the loss of behavioral control, often manifesting in aggression or profound, frozen withdrawal (Myles, 2003; Myles and Southwick, 1999).

The result is a phenomenological experience characterized by incoherence, fragmentation, and uncertainty, coupled with a passion for predictable systems through which to organize input and make sense of a world desperately in need of structuring (Belmonte, 2008). Individuals on the autism spectrum are known for their strict adherence to routines. They often develop extraordinary knowledge and/or ability in systematized and circumscribed domains: classification systems, for example, or schedules, or collections of facts about a single topic. Creating and maintaining a sense of coherence requires assistance from the outside world, through the appropriation and use of such cultural scaffolding from the external environment.

Naturalistic, ethnographic research on ASD has illustrated that some forms of cultural organization are more helpful with this process than others. Ochs, et al. (2004) conducted several years of in-depth ethnographic observation of children with autism in their daily lives. They found that the children were most successful in situations organized around a "stable symbolic and social order, of rules, schemata, and structural features." The children struggled, however, with the kinds of social practices that required "intuitively formulating strategies for interpreting and participating in emergent yet conventional social situations." The result is an orientation toward cultural practices that provide such explicit conventions. For example, Solomon (2004) found that children in the study were able to launch fictional narratives successfully, often because of the conventional language used to begin such stories, but often struggled to maintain a collaborative "co-telling" with a listener across multiple conversational turns. The children were more likely to tell "pre-packaged" fictional narratives taken from movies or television, rather than relate events from their own life; Solomon suggests that the pre-organization of events already "extracted from the experiential flow" and placed into "stable temporal and causal trajectories" relieves children of some of the organizational burden of creating coherence. Without external structure, this burden becomes unmanageable.

\section{The Culture of the Game: Structured Sociality}

At the Aspie camp, the structure of the roleplaying games set up a situation in which campers were able to engage in sustained, coordinated and spontaneous social practices, far more than was typical of their everyday lives. Roleplaying games offloaded the pressure to extract salient information and organize it into a gist by already arranging numerous components of social life into a shared, stable framework.

Much of this framework is introduced in the preparation phase for the game, which at the Aspie camp took up the first three days of each week. During this phase, players are presented with a "story intro" that describes the world where the story takes place and delineates some of its salient social dynamics. They might be told, for example, that the land 
is divided into three tribes-violent warriors, peaceable magicians, and sneaky thieves—and that the three tribes distrust each other. They might be taught to "give status" to characters such as kings and military captains who could have their character's heads cut off for insubordination. They might be told that their character dislikes another character on the team because of a past romance or quarrel. The expectation is that information shared in this way will be acted upon, and acted out, in game interactions. Consequently, selected elements of social interaction are extracted, highlighted, and prioritized in advance, lessening the demand to make these distinctions in the moment.

Preparation for game also involves creating and developing the characters that players will play in game. The ethnopsychology of in-game personality is highly structured and at least somewhat quantified. ${ }^{\mathrm{vi}}$ Characters are assigned greater or smaller amounts of certain qualities (such as strength, wisdom, dexterity, and charisma) sometimes by player choice, sometimes by rolling dice, often through a combination of the two. These traits have causal force in character interactions: if a character with high charisma asks your character to do something, respect for the game system entails that your character do it. Social interactions in game are therefore structured by a top-down, explicitly articulated, systematic, and shared set of behavioral norms and obligation - the very kind of system that Ochs et al. suggested is most productive of interactive success among individuals on the spectrum.

In addition to the explicit game rules, character behavior and interaction in game is also shaped by a widely known set of genre conventions drawn from fantasy literature and swords-and-sorcery games ${ }^{\mathrm{vii}}$. At the Aspie camp, character backstories and character development arcs tended to draw on a familiar set of narrative tropes-the angry orphan seeking revenge for the destruction of his village, the monster whose intrinsic goodness is understood only by his close friends, the lawless but good-natured rogue, and so on. Character dialogue tended toward the chivalric, in that it was formal, exaggeratedly polite, and characterized by one or two affectations that represented the character's inner life: a heavy sigh and faraway look, perhaps, or oblique references to a tragic past. Many characters had a sort of stock phrase, a signature line that well encapsulated their character's core dilemmas and which they broke out in response to numerous situations: Leo's character, for example, was half-human and half-orc and prone to murmuring I cannot help what I am ${ }^{\text {viii }}$. Adherence to genre conventions organized interactions in-game, by imposing an external, familiar, shared constraint on conversational possibilities while providing flexible scripts.

\footnotetext{
${ }^{\mathrm{vi}}$ The degree to which character development is constrained by a numeric system varies significantly by game type and player community, with some types of games being far more open-ended in their character-building practices. The Journeyfolk, on their own, play games that vary widely along the dimension of pre-established structure; for the Aspie camp, they hewed to a fairly traditional tabletop-inspired format that imported a great deal of those games' standard rules and regulations.

${ }^{\text {vii }}$ Those who were most familiar with the conventions of fantasy and speculative fiction genres tended to have the most engaged and well-elaborated game interactions. Players who drew on a different set of genres often had more trouble finding their social niche in the game. Murdoch the Muscle Man, for example, was drawn from a different genre tradition, that of old-time circus showmanship, and he had a hard time engaging with the high-drama relational world of the other characters, tending to interact far more with the non-player characters played by staff.

${ }^{v i i i}$ To provide a better-known example, this trope is both exemplified and gently satirized by the oft-repeated line "my name is Inigo Montoya; you killed my father; prepare to die" in the film The Princess Bride.
} 


\section{The Result: Structure and Social Coordination In Game}

This structure facilitated the "sustained co-telling" of narratives that Solomon (2004) identified as the most difficult for youth on the spectrum. I often marveled at the long backand-forth conversations that I had with the Aspie campers when we were in character, so different from our fragmented out-of-game interactions. During one game, for example, Gunnar and I took a long walk together. I was playing the guardian spirit of travelers, and he was playing a warrior prince from another world. To my amazement, we shared a long, coherent conversation, prolonged across multiple conversational turns, in which we each told the other about our different worlds - the strange plants and animals, the technology, the religious beliefs. I rarely managed to sustain these kinds of conversations with the Aspie campers in our day-to-day roles as modern-day American teen and adult (though it was sometimes a little bit easier within the formalized structure of our interviews), nor did I see them manage this with each other. Out of game, Gunnar's conversations were more likely to consist of him saying something like "po-TA-to! po-TA-to!" then poking his interlocutor in the shoulder and running off. Shared genre conventions provided an organizing structure that freed the campers up to improvise with each other a coordinated way, allowing for greater success at a challenging interactional task.

The congruence between the organization of roleplaying games and the needs of people with Asperger's provided both motivation to participate in these games and support for successful social coordination within them. They were therefore able to have experiences that were not as common in the chaos and confusion of their everyday lives: they could be valued contributors, both to their team of fellow heroic adventurers and to the greater project of creating the story as a whole.

\section{Narratives of the Game: Romances of Light and Shadow}

It was not only the structure of these story-games that created a congenial sociocultural space for the Asperger campers, however. The narrative content of the stories was also deeply resonant with their experience. The myths they drew on to create their characters tended to center around the experiences of protagonists who had been transformed by the intrusion of alien elements. The transformations brought not only extraordinary abilities, but also the potential for loss of control and a frightening discontinuity of selfhood and agency. The forces within these characters cut them off from the flow of normal human experience, but eventually brought them together in fellowship with a team of similarly affected others. They stories mirrored the campers' own experiences at the camp, as the radically discontinuous phenomenology and extreme strengths and weaknesses that characterize life with Asperger's Syndrome went from being a stigmatizing difference to a source of common ground.

Christy was 14 when she came to the camp. An avid reader with a goofy, random sense of humor, she was always wrapped in a black velvet cloak, even in the intense July heat. This was a fashion statement, certainly, but also a way to protect herself against the sensory input that could easily overwhelm her. "I have anger issues," she told me, shyly. When there was too much going on around her, when she was swarmed or crowded by groups of people, her 
perceptions of the world around her disintegrated into chaos. During these episodes of psychological fragmentation, she would strike at the people around her, in a way that felt completely out of her conscious control. "I never really remember my anger things" she told me. "I remember very slightly - I remember I was angry I hit the teacher! oh my gosh I hit the teacher! I'm gonna get expelled!" These experiences informed the multiplicity of her identity. "I'm half misanthrope" she told me during our interview, laughing. "Part misanthrope, part creature of darkness, part anthropophobic - I'm just messed up!"

The character that Christy created to play in our Legend of Aedril story, Aura Dragonsblood, was part demon, part timid young girl. A former student of dark magic who gave up her studies for fear of becoming too powerful, Aura's greatest fear was her own anger, because it allowed the demon to take her over. In such episodes, she became enormously strong, able to use powerful magic. But she also saw the world as her enemy, and could cause great destruction, even to her family and friends. By the end of the battle with the Orc King, Aura's duality had played a crucial role in saving the people of Rentin. Aura solved a riddle that proved that she is the direct descendant of Aedril, and therefore, like him, one of the very few who are able to wield both sword and magic spell. Her powers helped her defend her team against attack in a crucial battle.

Christy's best friend at the camp was a boy named Sylvester, a year younger than her and about half her size. Like Christy, Sylvester was creative and playful; like her, he was vulnerable to intense, frightening "meltdowns" when overwhelmed by emotion or by sensory input. These were so severe that he had been physically restrained on multiple occasions; once, he'd been psychiatrically hospitalized. The two of them immediately became inseparable, Sylvester tending to follow Christy's lead as they roved together through the forests surrounding the campground. Soon, Sylvester was playing half-demons, too. When possessed by his demon side, Feriek Ravenclaw would swing his sword wildly, rush into battle, take foolish risks, and fall down in trance-like fits. Christy, in character as Aura Dragonsblood, stayed protectively close by Feriek Ravenclaw, helping him manage his transformations and minimize their destructive consequences. Midway through the game, as we walked down the path, I heard her telling him how to use meditation and favorite songs to keep the wild, angry powers from emerging and taking over. As Aura was advising Feriek, Christy was also sharing with Sylvester strategies that I knew she had worked hard to cultivate in her everyday life.

These stories of demon possession, of co-existence with a force both powerful and dangerous, both self and other, metaphorically conceptualized and expressed the campers' own phenomenological experience of radical discontinuities in self-experience, identity and memory. The co-existence of strength and vulnerability encapsulated in these narratives captured essential features of the experience of living with Asperger's Syndrome-a condition that itself brought valued strengths (the ability to hyperfocus on a topic of interest, strengths in systematic thinking, an occasionally exquisite sensitivity to sensory input) as well as disabilities. Just as Aedril needed to be reconciled with the Golem, these stories provided an opportunity to bring together these different elements of the autism spectrum experience and provided a meaning-making system within which they could co-exist. The practices of roleplay were thus effective in part because they allowed for coordinated 
engagement with a shared mythology, one that both articulated the experiences of the Asperger campers and asserted the fundamental worth and acceptability of people who have those kinds of experiences. The stories enacted at the camp made space for extremes of experience—darkness and light, strength and terrifying vulnerability—and fit them into a narrative tradition within which these contrasts were accepted and even aesthetically appreciated.

\section{The Specificity of Community}

If these two aspects - the structure of practices, and the content of myths-were all it took to create a transformative practice, these findings would suggest a powerful and highly replicable intervention for youth on the spectrum. However, the picture is not nearly so simple nor so easily portable, as I learned when I tried to run similar camp programs, using a curriculum adapted from the Aspie camp, in several other therapeutic settings. The programs were well liked by participants and appreciated by families, but I could not shake a sense that the magic was not there. Returning to my notes about the Aspie camp, I saw that there was an important element that I had missed: the network of interpersonal relationships within which these narratives and practices were instantiated. As Bowman (2012) has observed, the psychosocial effects of roleplaying games depends a great deal on the formalized and informal group norms, intragroup dynamics, and roles available to and adopted by participants; all these factors shape the nature of the practice itself and its influence on participants.

The Journeyfolk well understand the impact of interpersonal relationships on the psychological and emotional consequences of role-play. They use a wide range of practices for cultivating a community within which players can feel safe to enact demon rages, facing down the monsters of their hearts. "You've just been terrified out of your mind" one of the Journeyfolk at the main camp said to me, attempting to explain why it was important to emerge from the game into a group of people that feel safe and familiar. "Maybe you've been completely broken, emotionally. Maybe you've been insane."

The Journeyfolk often told me that it was the close-knit, trusting nature of their community that made it possible to take these risks, to go into these dark places and then return, providing a deep-rooted sense of safety. A common refrain was "I came for the game, but I stayed for the community." They described the comfort of returning each year to a place where they felt accepted in all of their quirks and unusual interests. A number of traditions built and maintained an ethos of mutual trust, from "circles" where participants shared difficult life experiences and gave each other support, to trust exercises where campers and staff would form a web of interlinked arms, and a single person, lying stretched and suspended with eyes closed, would be passed down the chain. The goal was to let go and let yourself be carried by others, just as players must do with their improvisational partners in the game. During one such set of exercises, some jokes got cracked about dropping people; that night after dinner, a long impromptu meeting gave people a chance to share their reactions, process their feelings, and express their regret. "I can't imagine what it would be like to LARP with people you weren't this close to" said Andrea, one of the counselors. 
Long-term commitments to a mutually trusting community allowed for intense emotional work.

At the Aspie camp, we drew on many of the practices cultivated by the Journeyfolk: "circles" at the opening and closing of each day, trust exercises, encouragement to share "appreciations" of other campers and staff. Nonetheless, establishing this kind of community was a challenge given the little time we had. Some campers came for the whole summer, others only for a week; some campers knew each other well already and others did not. Emotions ran high, and the air was perpetually charged with violence and desire. One adolescent young man was fond of telling me he was going to slay me with his sword and then cut my dress open. Another counselor and I spoke to him about the impact his comments had on me and others; consequently, we had to work hard to convince him that we were not throwing him out. These forces were difficult to manage and contain in the absence of the trust that comes with longstanding relationships.

However, the involvement of the Unity Center, with its commitment to building autistic community and culture, went a long way toward creating a safe and mutually respectful place to role-play. Many campers had long-standing relationships with the Center and the school program it had run for several years, and they were steeped in its message of Aspie pride. The fact that the camp was made up entirely of youth on the spectrum, under conditions where their difference was valued instead of stigmatized, contributed to an overall ethos of mutual acceptance and support. Andrew, one of the CIT's, described to me what it was like to go from a prior experience of having been "the only autistic person in a school full of a whole bunch of, like, normal people, getting made fun of all the time" to having what he called "our own community ix":

We were all on the same boat-we were sailing in the same ship. We were all hyper, and makin' stuff up, our own stories and stuff - we were all like each other! We acted the same way as each other, and so we naturally fit in with each other, and we got along! As opposed to, like [another school he had attended], like a public high school, where you get picked on, and made fun of, because you're different. We're all different, so we got along! Because we all had the same conditions! We all, we knew what it was like to have it, so we all got along.

The particular social configuration of the camp, in concert with the Unity Center, changed the social force of Andrew's difference, from a cause of social marginalization, to a source of common ground.

Close social bonds also developed at the camp, and these relationships provided some of the participants with both new experiences and a new sense of acceptance and capability. Two of the CIT's, Burke and Leo, and a counselor, Imogen, who was herself diagnosed with Asperger's, formed a tight-knit trio over the course of the summer. Under the wary eyes of the older staff, they experimented with various sorts of previously unfamiliar intimacies: attending movies together, sitting on each other's laps, snuggling together in an increasingly

\footnotetext{
${ }^{i x}$ In the comment that follows, he is referring both to the camp and to the Asperger-specific school program run by the Unity Center, which he had attended with several of the others campers and CIT's.
} 
indistinguishable pile of black clothing. At the beginning of their tenure as counselors and CIT's, all three had struggled to manage the responsibilities they had been given; by the end, they felt far more mature, capable and competent. They attributed their growth to a number of factors, but above all, to their mutual support. Leo explained it through what he dubbed the "Theory of Extreme Awesomeness Ratio": when the awesomeness of one member of the group was low, the awesomeness of the other two would help to balance them out. Burke, a young man who was not prone to sugar-coating, said in our final meeting that the camp had been the best four weeks of his life. This was largely, he said, because of the ways Imogen and the rest of the group had "put up with" him. Sylvester's mother said something similar: the camp had been the best two weeks of Sylvester's life, she told me, because he felt accepted and enjoyed for who he was.

In our interview, Leo told me that his experience of belonging, both at the Aspie camp and the Unity Center school program it grew out of, transformed his understanding of both his diagnosis of Asperger's and himself. When I asked him, in our interview, how Asperger's had affected his life, he told me:

I think it's affected my life in many, many ways. First, it started out negatively, because at first I felt very estranged, and very unusual. And then it started to become a thing that made me part of something. Which - all that anyone wants is to be part - is to belong, somewhere. So, while it started negatively in me feeling very separated and very wrong - I became part of a group, and part of a society, part of people. I would say that it's opened up more doors for me than it's closed[...]For the majority of it, it's as much a blessing as anything else.

The sense of belonging that Leo experienced, at the camp and at the Unity Center more broadly, was a key part of his coming to understand Asperger's as "as much a blessing as anything else" and himself as no longer "very separated and very wrong." Shifting the meaning of Asperger's Syndrome shifted Leo's own sense of himself in his social world. By engaging Leo in the "work of culture," drawing him into "the best form of entertainment there is," the camp became a site of healing work for Leo. It did so not by changing his individual body, but by allowing for the reconfiguration of his social role and thus changing something profound in his sense of his own humanity: he went from feeling "very estranged" to experiencing himself as "part of something" and thus "part of people."

\section{Patrick's Tribe: Roleplay and The Spectrum of Neurodiversity}

Contributing to the lack of stigma around Asperger's Syndrome, at the camp, was the absence of a sharp dividing line between the Aspie campers and the supposedly neurotypical counselors. Their difference was understood less as a categorical distinction, and more as a gradient. For one thing, many of the counselors-even those without a formal diagnosisdid not identify themselves as being particularly neurotypical. Several of the most effective counselors at the Aspie camp were often said to be "on some spectrum or other"; this was offered as an explanation for their remarkable ability, their idiosyncracy, and a perceived connection between the two. The ethos of the Journeyfolk overall was frequently described with affectionate resignation as being "really ADHD" (shorthand for attention-deficit/ hyperactivity disorder). The counselors frequently described a sense of continuity between 
Asperger's Syndrome and their own quirky creativity, which often left them feeling out of place in the social mainstream. Many of the characteristics shared by the Aspie campershyperfocus on a topic of interest, discomfort with unstructured or implicitly structured sociality, an intense and high-contrast but often private emotional ethos, and a pull toward structured, genre-based cultural materials-were also common in the social community that surrounded the Journeyfolk. While these characteristics might be socially stigmatized in mainstream culture as "geeky," they were not understood by the Journeyfolk counselors as inherently problematic; rather, they were celebrated as sources of pleasure, affiliation, and pride.

Patrick, one of the Aspie counselors, described a feeling of deep loyalty, a kind of kinship with the Aspie campers. "They're my tribe," he enthused in a group meeting. When I asked him to explain what he meant, he elaborated:

Because we're interested in some of the same things: videogames, roleplaying, fantasy, things like that. And I was always identified as being a nerd. If I walk into room and there's a table with people wearing nice clothing, chilling, drinking beer I'm gonna go to little group of guys in the corner playing Magic cards ${ }^{\mathrm{x}}$. That's where my core goes to. That's where I feel most comfortable. There is something tribal about it, it's very strange.

Out of this sense of commonality arises a protectiveness toward those who struggle socially.

There's a sense of unfairness to it. That I get to do all the things that they do, play all the games that they play - and I also get to go talk to people, and they don't. Something happened to them where they don't get that luxury, of being able to shut that part of you down and go interact with the rest of the world. So I almost feel in a way this weird urge to defend them, to stand up and say: these are my people.

Similarly, William, one of the counselors, described the Aspie campers as being reminiscent of his crowd in high school. He described a profound sense of in-group loyalty toward others who shared the paired experiences of attraction to certain structured narrative practices and a history of social marginalization. Characterized by an ethos of social inclusiveness, his social group "made a premise of never leaving people out. We're the goofy kids, we're the nerds who play Magic cards and video games. We cannot be the ones rejecting people; we're the place people can go." Gaming practices, such as Magic cards and roleplaying games, that organize social interaction around the structured co-creation of highintensity narratives of power and transformation, organize those drawn to such practices into social collectives infused with significant personal meaning and identification.

The activities and social culture of the Journeyfolk had thus drawn together not only the Aspies but also those who shared aspects of their approach to the world that did not fall under a diagnostic label. As research on the "broader autism phenotype" has shown (Baron-

\footnotetext{
X"Magic cards" (the technical name is Magic: The Gathering) is a trading card game that shares many stylistic elements with traditional fantasy roleplaying games. In the game, wizards battle each other by casting magic spells and summoning fantastical creatures. These battles take place within a fictional "multiverse" that has also spawned a series of novels and an upcoming feature film; playing the game thus also instantiates an ongoing shared narrative in a highly structured game form. The game is notorious for being popular among those who might have difficulty negotiating less-mediated social interactions.
} 
Cohen, et al., 2001; Wheelwright, et al., 2010; Constantino and Todd, 2003), the cognitive style associated with ASC-focus on detail, relative strength in systematic thinking and relative weakness in social intuition, and a tendency to focus on a single topic rather than shifting between topics—occurs along a spectrum that begins long before the point at which these characteristics cause clinically significant impairment. Some (i.e., Baron-Cohen et al, 2002) assume that the covariance of these conditions is intrinsic to human neurodevelopment; others (Valla and Belmonte, 2013) have suggested that a correlation between initially dissociable traits emerges through a process of behavioral adaptation, becoming more entrenched over the course of development. In many cases, this pattern of characteristics can be beneficial, leading people into highly systematized careers in mathematics and engineering, or toward fulfilling engagements with enjoyable activities (Mottron, et al, 2009; Baron-Cohen et al, 1998). Manifestations of neurodiversity associated, in a more pronounced form, with autism spectrum conditions here serve as a potent force for the organization of cultural symbols, practices, narratives and relational ethics into a robust and recognizable schema: "the nerds who play Magic cards and don't reject people." That system then does its own work of attracting participants (who may "come for the game and stay for the community" or vice versa ${ }^{\mathrm{xi}}$ ) and offering them opportunities for personal transformation through symbolic and social engagement, as happened at the Journeyfolk camp.

The concept of "being a nerd" created a sort of a cultural bridge between Asperger's and the unmarked social positioning associated with neurotypicality. The counselors neither belonged to a neurotypical social mainstream, nor met criteria for Asperger's. Instead, they occupied and constituted a middle ground; in doing so, they illustrated a pathway to social participation and belonging. The cultural bridge of nerd identity created a sense of continuity, rather than a categorical distinction, between the identified patients and the surrounding culture into which they struggled to integrate, providing them with hope and motivation.

The Aspie campers aspired to participate in the mainstream camps and understood themselves to be potentially capable of doing so. They speculated often about what the other camps were like and what skills and personal resources they would need to develop in order to participate successfully in them. Near the end of the summer, Leo and Burke, accompanied by Imogen, successfully attended and played in some of the games at the main campground. Several of the campers and counselors went on to join the main camp in future summers. The combination of Asperger-specific space with perceived continuity between clinical diagnosis and positively valued social identification (the active, playful social life of geeks and nerds) created a milieu that was non-stigmatizing and offered possibilities for growth.

\footnotetext{
${ }^{x i}$ To give an accurate picture of the community, I should add that some of the Journeyfolk came to the camp for reasons other than an affinity with these aspects of roleplaying games, and did not consider themselves to be particularly geeky. Some were more interested in theater than in games; others were drawn to the playful spirit of the Collective, its close-knit community or its ethos of personal development and growth.
} 


\section{The Aspie Camp as Folk Healing System}

In this respect, the Aspie camp differed significantly from the kind of therapeutic settings the campers most frequently encountered, in which a sharp line is drawn between a sick patient and an (ostensibly) well healer. It is more like a folk healing system in which the healer must have some personal experience of the condition being treated, and perhaps most similar to processes of socialization within which novices learn through apprenticeship with more experienced members of a group (Rogoff, 1990; Rogoff, et al, 2007, Lave and Wenger, 1991).

I call the camp a "folk system" because its healing work is founded upon a meaning system and a body of knowledge that is shared between laypeople: the "subcultural information" (Fine, 1983 p. 33) that circulates among science fiction and fantasy aficionados. There is certainly a clear distinction between the campers and the expert counselors (who have the final say in the flow of the game-story, and make determinations about significant matters within it, like the kind and degree of powers a character can have). However, this differential constitutes a continuum along which campers can progress, not a chasm they cannot cross. After all, almost all of the Journeyfolk counselors were once campers themselves.

I call the camp a folk healing system because I believe that it heals, and that it does so in a way that is less consistent with biomedical understandings of healing and more consistent with the kinds of symbolic and social healing found in so-called folk practices, including scholarly work that considers psychotherapy in that light. With the guidance of counselors, campers reframe their experiences in terms of "culture-specific symbols in cultural myth" and invest powerful emotions in those symbols, and then campers and counselors together "manipulate [these] healing symbols" (Dow, 1986, p. 56). The process produces a sense of coherence, comprehensibility, manageability, and meaningfulness around experiences of distress (Antonevsky, 1979; Castillo, 2001), as well as a salutary reconfiguration of social relationships (Hinton and Lewis-Fernández, 2010). In Kleinman's (1978) terminology, participation in the camp could be understood to treat the "illness" (the life problems arising from autism spectrum conditions, particularly social estrangement) rather than the "disease" (the neurobiological substrate that underlies autistic difference). The change that the camp brings about is not a change in the biological body, nor does it take place entirely within the affected individual. Rather, it involves a collective change of meaning, through the investment of personal significance into shared narratives followed by a collaborative negotiation of what transpires within them. As Frank and Frank (1993) have observed, the combination of shared mythology, emotionally charged relationships, and activities that allow for the practice of new behavioral repertoires are powerful components of the "transformation of meaning" central to effective psychotherapy.

\section{Conclusion: Neurodiversity and the Constitution of Culture in a "World on the Move"}

The conference at which these papers were originally presented posed the question of how to study culture in a "world on the move." Examining the constitutive influence of 
neurodiversity on the organization of such sociocultural spaces can provide some insight into contemporary dilemmas in the social sciences. A number of scholars both within and outside anthropology (i.e., Appadurai, 1996; Olwig and Hastrup, 1997; Westbrook, 2008; Marcus, 1995; Gupta and Ferguson, 1997) have raised the question of how to conceptualize culture, and the fields within which it manifests, in a way that is not so deeply determined by physical locales and nation-state boundaries, while still accounting for the importance of spatial and geopolitical geographies, physical co-presence, and embodiment. Looking at the relationship between neurocognitive variation and cultural materials, identifying points of affinity and congruence and examining their manifestations and outcomes can contribute significantly to this project. Developing an enculturated identity often entails selecting from a broad range of lifeways and opportunities for engagement, a process constrained by both structural and physical givens (Beck and Beck-Gernsheim, 2002; Furlong and Cartmel, 1997). Elective engagement with "patterned practices" both shapes and is shaped by embodied processes that can be productively investigated, at least in part, through the neurosciences (Roepstorff, et al, 2010, Lende and Downey, 2012). When Patrick calls the Aspie campers his "tribe," he is invoking an emerging form of "mediated kinship" (Rapp and Ginsburg, 2001) born not out of blood relation and shared homeland, but embodied similarities in cognition working in tandem with shared cultural materials. To understand the work of culture under contemporary conditions requires that we attend to the interplay between neurodiversity and the affordances of cultural materials; it is in this interaction that much of the building and maintenance of culture takes place.

Here, I have aimed to show that autism, and the broader spectrum or "phenotype" of which it is a part, is a productive site for examining the interplay between neurocognitive variation and cultural practice. At the Aspie camp, autism was the catalyst for the creation of a new and generative sociocultural space-motivated not by the impairments that can come with the autistic cognitive style, but by the capacities it brought for shared enjoyment. By looking at a space in which the autism spectrum brought people together into a community centered on aesthetics, pleasure, and play, I hope to have emphasized the power of autism and other forms of neurocognitive variation for organizing culture.

\section{References Cited}

American Psychiatric Association. Diagnostic and Statistical Manual of Mental Disorders. 5. Washington, DC: American Psychiatric Association; 2013.

Antonevsky, Aaron. Health, Stress, and Coping. San Francisco, CA: Jossey-Bass; 1979.

Appadurai, Arjan. Modernity at Large: Cultural Dimensions of Globalization. Minneapolis: University of Minnesota Press; 1996.

Atwood, Tony. The Complete Guide to Asperger's Syndrome. London: Jessica Kingsley Press; 2007.

Baez, Sandra; Rattazzi, Alexia; Gonzalez-Gadea, María L.; Torralva, Teresa; Vigliecca, Nora Silvana; Decety, Jean; Manes, Facundo; Ibanez, Agustin. Integrating Intention and Context: Assessing Social Cognition in Adults with Asperger Syndrome. Frontiers in Human Neuroscience. 2012; 6:302. [PubMed: 23162450]

Baranek, Grace. Efficacy of Sensory and Motor Interventions for Children with Autism. Journal of Autism \& Developmental Disorders. 2002; 32(5):397-422. [PubMed: 12463517]

Baron-Cohen, Simon. Mindblindness: An Essay on Autism and Theory of Mind. Cambridge, Mass: MIT Press; 1995. 
Baron-Cohen, Simon. The Extreme Male Brain Theory of Autism. Trends in Cognitive Sciences. 2002; 6:248-254. [PubMed: 12039606]

Baron-Cohen, Simon; Richler, Jennifer; Bisarya, Dheraj; Gurunathan, Nhishanth; Wheelwright, Sally. The Systemizing Quotient: An Investigation of Adults with Asperger Syndrome or HighFunctioning Autism, and Normal Sex Differences. Theme Issue, "Autism Mind and Brain", Philosophical Transactions: Biological Sciences. 2003; 358:361-374.

Baron-Cohen, Simon; Wheelwright, Sally; Skinner, Richard; Joanne, Martin; Clubley, Emma. The Autism-Spectrum Quotient (AQ): Evidence from Asperger syndrome/high- functioning Autism, Males and Females, Scientists and Mathematicians. Journal of Autism and Developmental Disorders. 2001; 31:5-17. [PubMed: 11439754]

Beck, Ulrich; Beck-Gernsheim, Elizabeth. Individualization: Institutionalized Individualism and its Social and Political Consequences. London: Sage Press; 2002.

Belmonte, Matthew. Human, But More So: What the Autistic Brain Tells Us About the Process of Narrative. In: Osteen, Mark, editor. Autism and Representation. London: Routledge; 2008.

Bowman, Sarah. Social Conflict in Role-Playing Communities: An Exploratory Qualitative Study. International Journal of Role-Playing. 2012; 4:4-25.

Bruner, Jerome; Feldman, Carol. Theories of Mind and the Problem of Autism. In: Baron-Cohen, Simon; Tager-Flusberg, Helen; Cohen, Donald J., editors. Understanding Other Minds: Perspectives from Autism. Oxford: Oxford University Press; 1993.

Brunsdon, Victoria; Happé, Francesca. Exploring the "Fractionation" of Autism at the Cognitive Level. Autism. 2014; 18(1):17-30. [PubMed: 24126870]

Castillo, Richard. Lessons from Folk Healing Practices. In: Tseng, Wen-Shing; Streltzer, Jon, editors. Culture and Psychotherapy: A Guide to Clinical Practice. Washington, DC: American Psychiatric Press; 2001.

Chapin, Bambi. Transforming Possession: Josephine and the Work of Culture. Ethos. 2008; 36(2): 220-245.

Constantino, John; Todd, Richard. Autistic Traits in the General Population. Archives of General Psychiatry. 2003; 60:524-530. [PubMed: 12742874]

Dow, James. Universal Aspects of Symbolic Healing: A Theoretical Synthesis. American Anthropologist. 1986; 88(1):56-69.

Dunn, Winnie; Saiter, Jessica; Rinner, Louanne. Asperger Syndrome and Sensory Processing: A Conceptual Model and Guidance for Intervention Planning. Focus on Autism and Other Developmental Disabilities. 2002; 17(3):172-185.

Fine, Gary. Shared Fantasy: Role Playing Games as Social Worlds. Chicago: University of Chicago Press; 1983.

Frank, Jerome; Frank, Julia. Persuasion and Healing: A Comparative Study of Psychotherapy. Baltimore: Johns Hopkins Press; 1993.

Frith, Uta. Why We Need Cognitive Explanations of Autism. The Quarterly Journal of Experimental Psychology. 2012; 65(11):2073-2092. [PubMed: 22906000]

Frith, Uta. Autism: Explaining the Enigma. Oxford, UK: Basil Blackwell; 1989.

Furlong, Andy; Cartmel, Fred. Young People and Social Change: Individualization and Risk in Late Modernity. Berkshire, UK: McGraw Hill International; 1997.

Geertz, Clifford. The Interpretation of Cultures: Selected Essays. New York: Basic Books; 1973.

Granader, Yael; Wallace, Gregory; Hardy, Kristina; Yerys, Benjamin; Lawson, Rachel; Rosenthal, Michael; Wills, Meagan; Dixon, Eunice; Pandey, Juhi; Penna, Rebecca; Schultz, Robert; Kenworthy, Lauren. Characterizing the Factor Structure of Parent Reported Executive Function in Autism Spectrum Disorders: The Impact of Cognitive Inflexibility. Journal of Autism and Developmental Disorders. 2014; 44(12):3056-3062. [PubMed: 24972681]

Gupta, Akhil; Ferguson, James. Discipline and Practice: The "Field" as Site, Method and Location in Anthropology. In: Gupta, Akhil; Ferguson, James, editors. Anthropological Locations: Boundaries and Grounds of a Field Science. Berkeley: University of California Press; 1997.

Happé, Francesca; Frith, Uta. The Weak Coherence Account: Detail-focused Cognitive Style in Autism Spectrum Disorders. Journal of Autism \& Developmental Disorders. 2006; 36(1):5-25. [PubMed: 16450045] 
Hinton, Devon; Lewis-Fernández, Roberto. Idioms of Distress Among Trauma Survivors: Subtypes and Clinical Utility. Culture, Medicine and Psychiatry. 2010; 34:209-218.

Kana, Rajesh; Libero, Lauren; Hu, Christi; Deshpande, Hrishikesh; Colburn, Jeffrey. Functional Brain Networks and White Matter Underlying Theory-of-Mind in Autism. Social, Cognitive and Affective Neuroscience. 2014; 9(1):98-105. [PubMed: 22977198]

Kleinman, Arthur. Concepts and a Model for the Comparison of Medical Systems as Cultural Systems. Social Science and Medicine. 1978; 12:85-93. [PubMed: 358402]

Lave, Jean; Wenger, Etienne. Situated Learning: Legitimate Peripheral Participation. NY: Cambridge University Press; 1991.

Lende, Daniel; Downey, Greg, editors. The Encultured Brain: An Introduction to Neuroanthropology. Cambridge: MIT Press; 2012.

Losh, Molly; Capps, Lisa. Narrative Ability in High-Functioning Children with Autism or Asperger's Syndrome. Journal of Autism \& Developmental Disorders. 2003; 33(3):239-251. [PubMed: 12908827]

Marcus, George. Ethnography in/of the World System: The Emergence of Multi-Sited Ethnography. Annual Review of Anthropology. 1995; 24:95-117.

Myles, Brenda Smith. Behavioral Forms of Stress Management for Individuals with Asperger Syndrome. Child and Adolescent Psychiatric Clinics of North America. 2003; 12:123-141. [PubMed: 12512402]

Myles, Brenda Smith; Southwick, Jack. Asperger Syndrome and Difficult Moments: Practical Solutions for Tantrums, Rage, and Meltdowns. Shawneee Mission, KS: Autism Asperger Publishing Co; 1999.

Obeyesekere, Gananath. Medusa's Hair: An Essay on Personal Symbols and Religious Experience. Chicago: University of Chicago Press; 1981.

Obeyesekere, Gananath. The Work of Culture: Symbolic Transformation in Psychoanalysis and Anthropology. Chicago: University of Chicago Press; 1990.

Ochs, Elinor; Kremer-Sadlik, Tamar; Sirota, Karen Gainer; Solomon, Olga. Autism and the Social World: An Anthropological Perspective. Discourse Studies. 2004; 6(2):147-183.

Olu-Lafe, Olufemi; Liederman, Jacqueline; Tager-Flusberg, Helen. Is the Ability to Integrate Parts into Wholes Affected in Autism Spectrum Disorder? Journal of Autism and Developmental Disorders. 2014; 44(10):2652-2660. [PubMed: 24737003]

Olwig, Karen Fog; Hastrup, Kristen, editors. Siting Culture: The Shifting Anthropological Object. New York: Routledge; 1997.

Ozonoff, Sally; Pennington, Bruce F.; Rogers, Sally J. Executive Function Deficits in HighFunctioning Autistic Individuals: Relationship to Theory of Mind. Journal of Child Psychology \& Psychiatry \& Allied Disciplines. 1991; 32:1081-1105.

Pennington, Bruce F.; Ozonoff, Sally. Executive Functions and Developmental Psychopathology. Journal of Child Psychology \& Psychiatry \& Allied Disciplines. 1996; (37):51-87.

Prince-Hughes, Dawn, editor. Aquamarine Blue 5: Personal Stories of College Students with Autism. Athens: Swallow Press/Ohio University Press; 2002.

Robinson, Sally; Goddard, Lorna; Dritschel, Barbara; Wisley, Mary; Howlin, Pat. Executive Functions in Children with Autism Spectrum Disorders. Brain and Cognition. 2009; 71:362-368. [PubMed: 19628325]

Roepstorff, Andreas; Niewöhner, Jörg; Beck, Stefan. Enculturing Brains through Patterned Practices. Neural Networks. 2010; 23:1051-1059. [PubMed: 20813499]

Rogoff, Barbara. Apprenticeship in Thinking: Cognitive Development in Social Context. New York: Oxford University Press; 1990.

Rogoff, Barbara; Moore, Leslie; Najafi, Behnosh; Dexter, Amy; Correa-Chávez, Maricela; Solis, Jocelyn. Children's Development of Cultural Repertoires Through Participation in Everyday Routines and Practices. In: Grusec, JE.; Hastings, PD., editors. Handbook of Socialization: Theory and Research. New York: Guilford Press; 2007.

Safran, Joan S. Supporting Students with Asperger's Syndrome in General Education. TEACHING Exceptional Children. 2002; 34(5):60-66. 
Solomon, Olga. Narrative Introductions: Discourse Competence of Children with Autistic Spectrum Disorders. Discourse Studies. 2004; 6(2):253-276.

Westbrook, David. Navigators of the Contemporary: Why Ethnography Matters. Chicago: University of Chicago Press; 2008.

Wheelwright, Sally; Auyeung, Bonnie; Allison, Carrie; Baron-Cohen, Simon. Defining the Broader, Medium and Narrow Autism Phenotype Among Parents Using the Autism Spectrum Quotient (AQ). Molecular Autism. 2010; 1:10. [PubMed: 20678260]

Valla, Jeffrey; Belmonte, Matthew. Detail-oriented Cognitive Style and Social Communicative Deficits, Within and Beyond the Autism Spectrum: Independent Traits that Grow into Developmental Interdependence. Developmental Review. 2013; 33:371-398.

Vanegas, Sandra; Davidson, Denise. Investigating Distinct and Related Contributions of Weak Central Coherence, Executive Dysfunction, and Systemizing Theories to the Cognitive Profiles of Children with Autism Spectrum Disorders and Typically Developing Children. Research in Autism Spectrum Disorders. 2015; 11:77-92. 